\title{
Vertical migration behaviour in the northern krill Meganyctiphanes norvegica is influenced by moult and reproductive processes
}

\author{
G. A. Tarling ${ }^{1, *}$, J. Cuzin-Roudy ${ }^{2}$, F. Buchholz ${ }^{3}$ \\ ${ }^{1}$ Scottish Association for Marine Science, PO Box 3, Oban, Argyll PA34 4AD, Scotland, UK \\ ${ }^{2}$ Observatoire Océanologique, UPMC CNRS INSU LOBEPM, Océanographie biochimique et Ecologie, BP 28, 06230 , \\ Villefranche-sur-Mer, France \\ ${ }^{3}$ Biologische Anstalt Helgoland, Stiftung AWI, Meeresstation, Postfach 180, 27483 Helgoland, Germany
}

\begin{abstract}
A population of the northern krill Meganyctiphanes norvegica was sampled between 24 July and 3 August 1998 in the Alkor Deep, Kattegat, in order to investigate the influence of sexual and developmental factors on the vertical distribution of adult krill. Depth-discrete samples of krill were taken with a $1 \mathrm{~m}^{2}$ MOCNESS net at the cardinal times of day (midnight, midday, sunrise and sunset). Specimens were immediately measured and categorised for moulting and spawning status. Further samples were preserved for detailed analysis in the home laboratory. Results showed that the population concentrated in the deep $(80$ to $100 \mathrm{~m})$ during day-time but segregated vertically during nighttime. Moulting occurred in the deep during night-time, away from the main part of the non-moulting population, which was located between 80 and $50 \mathrm{~m}$. Spawning females were most evident in the uppermost depth interval ( 30 to $5 \mathrm{~m}$ ). Moulting at night in the deepest layers may be viewed as a mechanism to avoid cannibalism whilst in a vulnerable condition. Spawning in the warm upper layers accelerates reproductive processes and may also reduce the depth to which the eggs sink before hatching into nauplii.
\end{abstract}

KEY WORDS: Northern krill · Euphausiids - Swarming · Diel vertical migration · Spawning · Moulting Sexual behaviour

\section{INTRODUCTION}

Northern krill Meganyctiphanes norvegica, M. Sars 1857 has a wide geographic range and is found in many areas of the North Atlantic and Mediterranean (Boucher \& Thiriot 1972, Lindley 1982). Northern krill typically swarm (e.g. Simard et al. 1986, Buchholz et al. 1995, Tarling et al. 1999) and are strong vertical migrators (Mauchline \& Fisher 1969, Mauchline 1980), exhibiting a normal diel vertical migration pattern of ascent into the upper layers at dusk and descent at dawn (see review by Longhurst 1976). The vertical distance travelled during these migrations varies between

\footnotetext{
•E-mail:gant@dml.ac.uk
}

locations. In the Clyde Sea and the Kattegat, which are both relatively shallow, krill will move a vertical distance of $70 \mathrm{~m}$ between their day- and night-time depths (Mauchline 1960, Buchholz et al. 1995) whilst in the deep Ligurian Sea, they travel over $500 \mathrm{~m}$ (Velsch 1997). Of particular interest is the indication that vertical migration into the upper layers at night-time is not performed by the entire population every night. Greene et al. (1992), for instance, found that a population of $M$. norvegica in the Gulf of Maine which resided at depth (200 to $250 \mathrm{~m}$ ) during day-time segregated at night into 2 groups; one which performed a synchronised migration to the surface $(50$ to $0 \mathrm{~m})$ and another which remained in the deep. Observations made by Youngbluth et al. (1989) using a submersible in the Gulf of Maine and canyons south of Georges 
Bank led them to believe that only a small part of the population of $M$. norvegica migrated upwards.

The majority of literature devoted to vertical migration in Meganyctiphanes norvegica has dealt with its relationship to feeding (e.g. Sameoto 1980, Simard et al. 1986, Bamstedt \& Karlson 1998, Onsrud \& Kaartvedt 1998) and predator avoidance (e.g. Kaartvedt et al. 1996, Onsrud \& Kaartvedt 1998). Although these approaches are satisfactory in dealing with the basic forces that induce krill to migrate vertically, such studies have not directly addressed the question of why night-time segregation occurs. The possibility that female spawning is influential in this respect is indicated by Nicol (1984), who found surface swarms of $M$. norvegica in the Bay of Fundy that were dominated by females in pre- or post-spawning condition together with large numbers of krill eggs in the plankton. Furthermore, the fact that moult and reproductive cycles are interlinked in female krill (Cuzin-Roudy \& Buchholz 1999) suggests that more than 1 adult developmental process may influence vertical migration behaviour.

The aim of the present study was to examine the relationship between vertical migration and adult developmental cycles by documenting the size, sex, moult stage and state of maturity of female krill throughout the water column over the day/night cycle. The choice of the Alkor Deep (Kattegat) was particularly crucial since the population was known to be stable and not subject to a significant degree of import and export during the time of study (Buchholz \& Boysen-Ennen 1988), which may otherwise bias observed patterns. The study fell within summer when the krill were known to reproduce (April to October, Boysen \& Buchholz 1984, Cuzin-Roudy \& Buchholz 1999). Samples from 7 full day/night cycles were obtained within a 13 d period.

\section{MATERIALS AND METHODS}

Meganyctiphanes norvegica was sampled in the Alkor Deep (bottom depth: $134 \mathrm{~m}$ ) over 7 full day/night cycles between 24 July and 26 July 1998 and between 30 July and 3 August 1998. Samples were taken at the cardinal times of day, which are noon (solar time), dusk, midnight (solar time) and dawn, and were equivalent to the local times (universal time coordinated +2 ) of 14:00,22:00, 02:00 and 05:00 h respectively. Net samples were obtained with a $1 \mathrm{~m}^{2}$ MOCNESS net (multiple opening net with environmental sensing system, Wiebe et al. 1976, 1985) on which a total of six $2 \mathrm{~mm}$ mesh nets were used (Nets 2 to 7 ). These nets were opened and closed whilst the gear was being hauled in such that the water column was sampled in the following discrete depth intervals: $100-80,80-65,65-50,50-30$ and 30-5 m. Temperature and salinity was measured by sensors attached to the MOCNESS frame and also by CTD casts carried out at 12:00 and 00:00 h each day. Fluorescence profiles were obtained during the 12:00 h deployments.

The krill from net catches were rapidly sorted according to sex and measured to the nearest millimetre from the anterior limit of the eyes to the end of the telson. Those specimens with a soft cuticle and a flaccid body were classified as 'moulting', i.e. in moult stages (MS) $\mathrm{D}_{3}$ (Day 3) (resorption of old cuticle), $\mathrm{E}$ (ecdysis) or A (recently moulted with a new cuticle that is still soft) as described for Meganyctiphanes norvegica in former studies (Buchholz 1991, Cuzin-Roudy \& Buchholz 1999). Females with a blue-grey appearance of the ovary were classified as 'ready to spawn', i.e. ready for either the first (sexual development stage [SDS] 4) or second (SDS 5 $)$ spawning event of a spawning moult cycle following Cuzin-Roudy (1993) and Cuzin-Roudy \& Buchholz (1999). The total number of krill measured and classified during the sampling period was over 13000 specimens from a total of 96 MOCNESS deployments.

Krill samples from 2 MOCNESS deployments were preserved in $10 \%$ formalin for more detailed staging of ovarian development and moult. One sample was taken from $80 \mathrm{~m}$ on 25 July at $14: 00 \mathrm{~h}$, which was within a dense krill swarm, and another set of samples from 3 depth intervals (100 to $80 \mathrm{~m}, 65$ to $50 \mathrm{~m}$ and 20 to $10 \mathrm{~m}$ ) on 1 August at 02:00 h. SDSs were assessed from the structure of the ovary and the degree of oocyte development following Cuzin-Roudy (1993) and Cuzin-Roudy \& Buchholz (1999). The females were all in reproductive state (full thelycum) and were classified as 'vitellogenic' (SDS 3), 'spawning' (SDS 4 and SDS $5_{1}$ ) or 'postspawn' (SDS $5_{2}$ and SDS 6). The moult staging of preserved krill was adapted from Buchholz (1991) and Cuzin-Roudy \& Buchholz (1999), and simplified because of the disturbance caused by formalin to krill tissues, especially at apolysis and $D_{0}$. Krill were simply classified as 'moulting' if they were at MS $D_{3} / E$ and $A$, 'postmoult' if at MS B, C and $D_{0}$ or 'premoult' if at $M S D_{1}, D_{2}$ and early $D_{3}$

A chi-square test for the comparison of medians (Zar 1996) was used to check for differences in the size distribution of krill at different depth intervals. A single factor analysis of variance test (ANOVA) was used to examine differences in krill concentration between days at discrete times and depth intervals. A 2-sample t-test (assuming unequal variance) was used to test the null hypothesis that there was no difference between the numbers of moulting males and females at discrete depths and times. 


\section{RESULTS}

\section{Hydrographic conditions}

Hydrographic data obtained during this cruise are examined in greater detail in Matthews et al. (1999) and only a brief synopsis is given here. Temperature, salinity and chlorophyll a (chl a) conditions during the sampling campaign were exemplified by profiles taken on 30 July 1998 (Fig. 1). Surface temperatures were approximately $16^{\circ} \mathrm{C}$ and bottom water below $80 \mathrm{~m}$ was about $6.5^{\circ} \mathrm{C}$. A distinct thermocline was apparent at $30 \mathrm{~m}$, with a temperature step of around $5^{\circ} \mathrm{C}$. Salinity increased steadily from 20 PSU in the surface layers to $34 \mathrm{PSU}$ at $30 \mathrm{~m}$. There was little further increase in salinity through the lower part of the water column. The chl a maximum was found at $10 \mathrm{~m}$, where values reached $0.5 \mathrm{mg} \mathrm{chl} \mathrm{a} \mathrm{m}{ }^{-3}$. Chl a values at all other depths were approximately half of the Chl a maximum.

\section{Size distribution}

Fig. 2 shows the overall size distribution of krill from all the net catches taken in the Alkor Deep from 24 July to 3 August 1998. The distribution was unimodal and the dominant size class of 31 to $32 \mathrm{~mm}$ corresponded to $1 \mathrm{yr}$ old individuals (Group I) when compared with growth curves provided by Boysen \& Buchholz (1984) for Meganyctiphanes norvegica in the Kattegat. The size distribution found during the present study was therefore considered to be typical for a summer situation in the Kattegat.

\section{Vertical distribution patterns in abundance}

Fig. 3 and Table 1 present the concentration of individuals at 5 depth intervals during the 4 cardinal times of the day/night cycle, averaged over the study period At $14: 00 \mathrm{~h}$, almost the entire sampled population resided in the deepest depth interval $(100$ to $80 \mathrm{~m})$ at an average concentration of 10.91 ind. $\mathrm{m}^{-3}$ (Table 1).

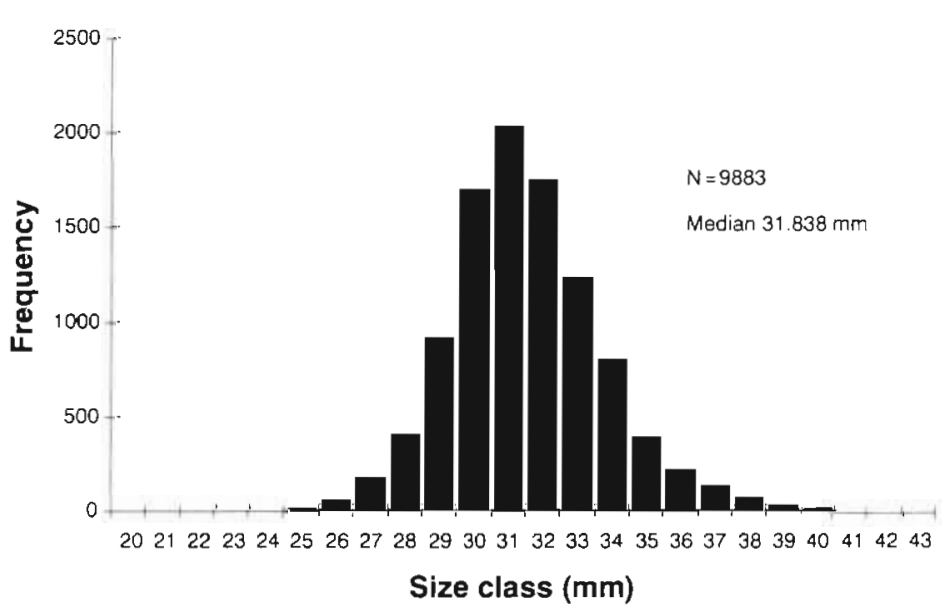

Fig. 2. Size frequency of the Meganyctiphanes norvegica population in the Alkor Deep established from all samples taken between 24 July and 3 August 1998 (size bins are labelled in relation to the minimum size within the category)
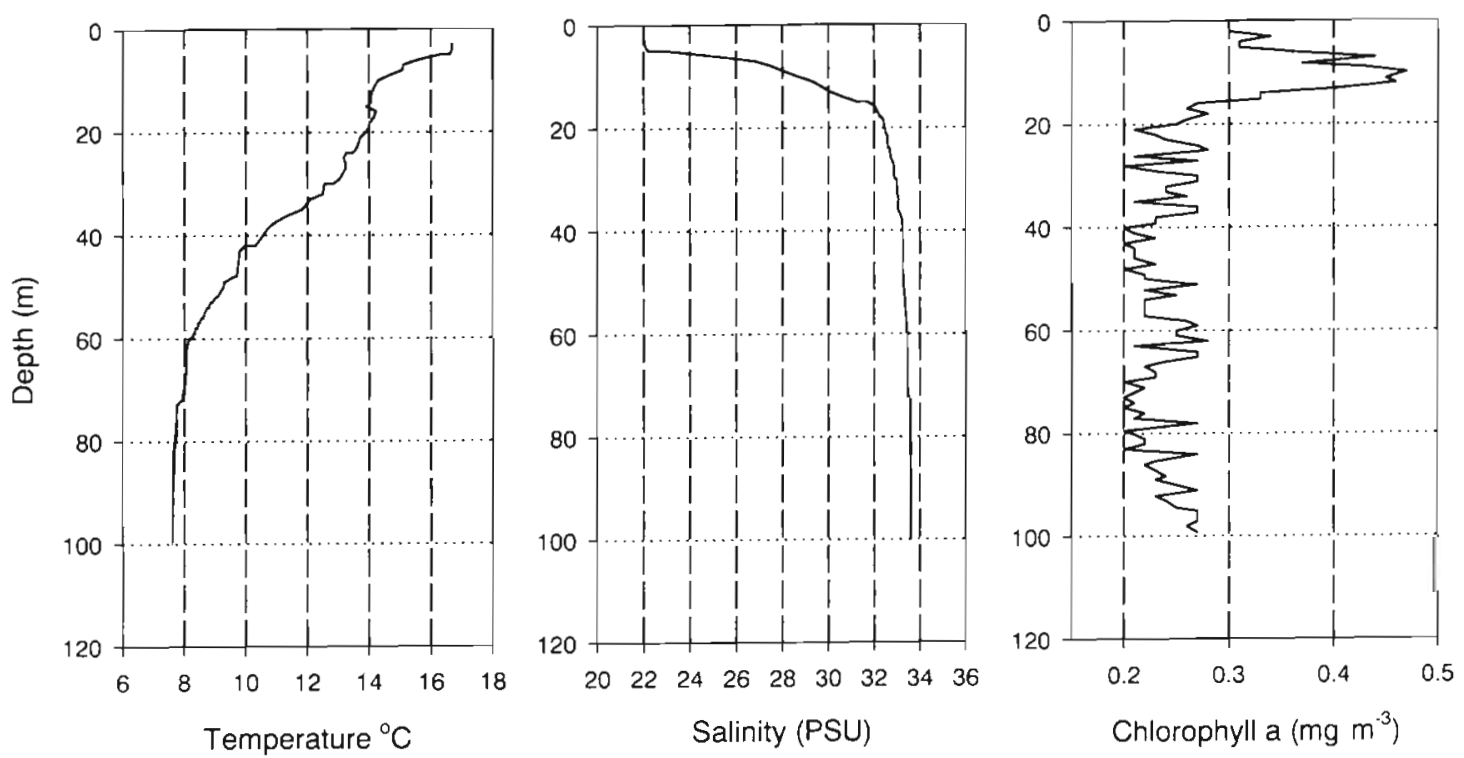

Fig. 1. Temperature, salinity and chlorophyll a profiles taken on 30 July 1998 in the Alkor Deep, Kattegat 


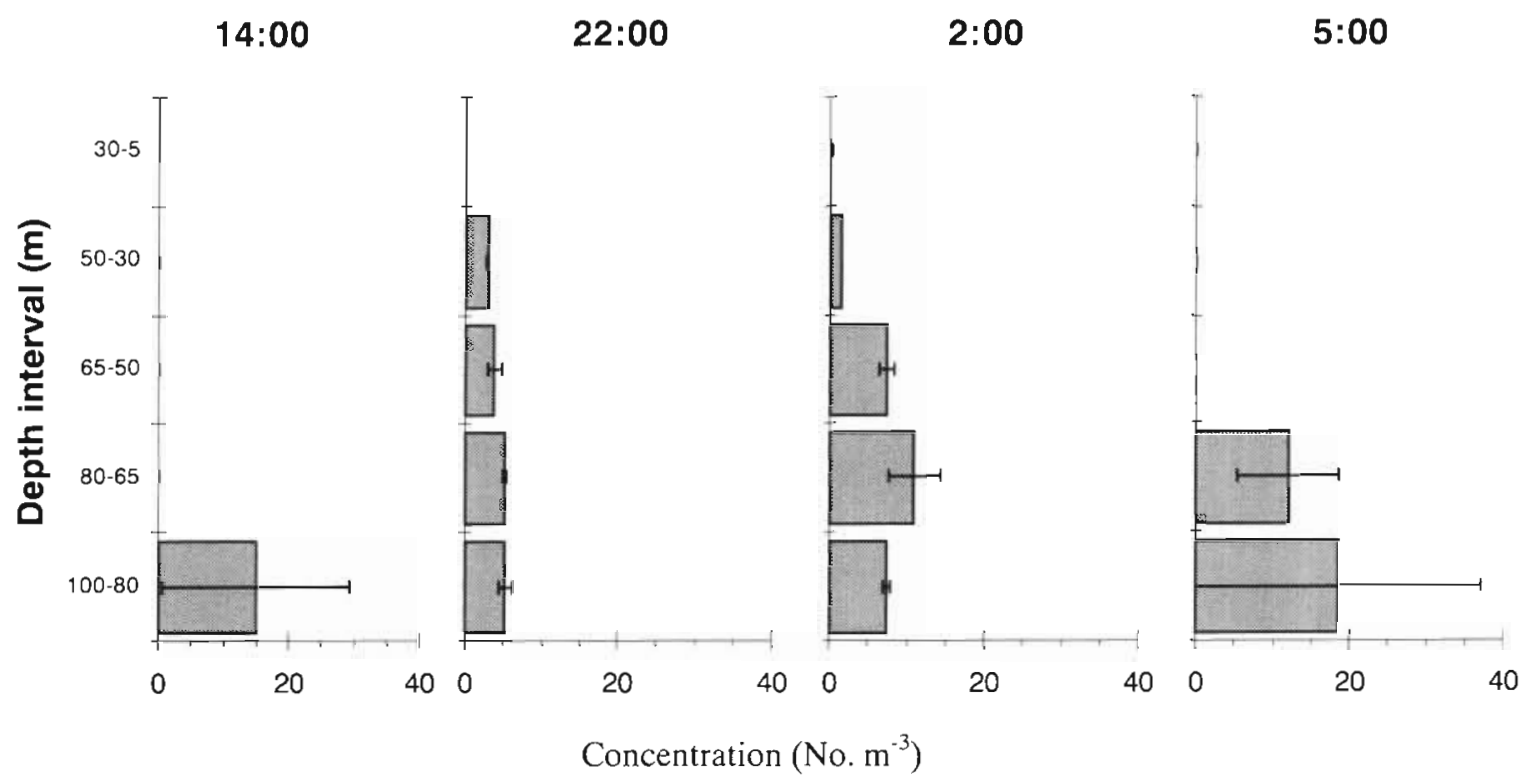

Fig. 3. Concentration of Meganyctiphanes norvegica (ind. $\mathrm{m}^{-3}$ ) in the Alkor Deep averaged over 7 full day/night cycles within the period 24 August to 3 August 1998 (with $95 \%$ confidence intervals)

By 22:00 h, there was a clear pattern of vertical migration into the upper depth intervals. Concentrations increased significantly in every depth interval above $80 \mathrm{~m}$ whilst the concentration between 100 and $80 \mathrm{~m}$ correspondingly decreased by a half. Nevertheless, concentrations in the uppermost depth interval (30 to $5 \mathrm{~m})$ were relatively low $\left(0.09\right.$ ind $\left.\mathrm{m}^{-3}\right)$ compared with other depth intervals. At 02:00 h, the concentration between 30 and $5 \mathrm{~m}$ increased to 0.23 ind. $\mathrm{m}^{-3}$ whilst concentrations at all other depth intervals decreased from the levels observed at 22:00 $\mathrm{h}$. The relative proportion of krill in each depth interval was nevertheless similar to the one at 22:00 h with the majority of krill being located between 80 and $50 \mathrm{~m}$. At 05:00 h, a significant decrease in concentrations above $65 \mathrm{~m}$ and a corresponding 2- to 3 -fold increase below $65 \mathrm{~m}$ indicated a descent to the deepest layers.

Table 2 shows the depth-integrated abundance of krill at each of the 4 cardinal times, averaged over the

Table 1. Concentration of Meganyctiphanes norvegica (ind $\mathrm{m}^{-3}$ ) in the Alkor Deep at the 4 cardinal times averaged over the study period (parentheses denote $95 \%$ confidence interval)

\begin{tabular}{|c|c|c|c|c|}
\hline \multirow[t]{2}{*}{ Depth (m) } & \multicolumn{4}{|c|}{ Ind. $\mathrm{m}^{-3}$} \\
\hline & $14: 00 \mathrm{~h}$ & $22: 00 \mathrm{~h}$ & $02: 00 \mathrm{~h}$ & 05:00 h \\
\hline $30-5$ & $0.01 \quad(0.01)$ & $0.09 \quad(0.08)$ & $0.23(0.09)$ & $0.02(0.01)$ \\
\hline $50-30$ & $0.01 \quad(0.01)$ & $3.29 \quad(2.94)$ & $1.39(0.40)$ & $0.03(0.00)$ \\
\hline $65-50$ & $0.02(0.01)$ & $12.68(12.47)$ & $3.70 \quad(2.05)$ & $0.16(0.00)$ \\
\hline $80-65$ & $0.14 \quad(0.11)$ & $11.56 \quad(9.42)$ & $5.41 \quad(3.75)$ & $5.25(6.48)$ \\
\hline $100-80$ & $10.91(7.84)$ & $5.42 \quad(4.97)$ & $3.36(2.20)$ & $11.24(18.67)$ \\
\hline
\end{tabular}

study period. It is evident from the $95 \%$ confidence intervals that the variation in krill concentrations between days is large. Furthermore, a single factor ANOVA found krill concentrations at $02: 00 \mathrm{~h}$ to be significantly different between days $(p=0.05)$. For this reason, subsequent results use the relative proportion rather than the absolute concentration of krill categories in each MOCNESS deployment.

\section{Male and female vertical distribution patterns}

Fig. 4 presents the ratio of females to males in each depth interval at the 4 cardinal times averaged over the study period. As indicated in Fig. 3, the population concentrated in the deep every day, which makes the 100 to $80 \mathrm{~m}$ sample at 14:00 h a suitable one for examining the sex ratio of the population. Data from this sample showed that females were, on average, more abundant than males by a ratio of $2: 1$. During the night-time period, significant departures from this overall ratio occurred in different parts of the water column. At both 22:00 and 02:00 h, in the 100 to $80 \mathrm{~m}$ depth interval, the abundance of females was slightly smaller than that of males. However, the ratio consecutively increased in favour of females moving up through the water column such that $85 \%$ of all individuals caught between 30 and $5 \mathrm{~m}$ at 02:00 h were female. The overall picture therefore indicated that a larger 
Table 2. Depth-integrated abundance (ind. $\mathrm{m}^{-2}$ ) of Meganyctiphanes norvegica in the Alkor Deep at the 4 cardinal times averaged over the study period showing $95 \%$ confidence Iimits and p-value for single factor ANOVA testing for the difference between days

\begin{tabular}{|c|c|c|c|c|}
\hline & \multicolumn{4}{|c|}{ Ind. $\mathrm{m}^{-2}$} \\
\hline & $14: 00 \mathrm{~h}$ & $22: 00 \mathrm{~h}$ & $02: 00 \mathrm{~h}$ & $05: 00 \mathrm{~h}$ \\
\hline Mean & 220.85 & 540.15 & 232.34 & 306.96 \\
\hline $\begin{array}{l}95 \% \text { confidence } \\
\text { limits }\end{array}$ & \pm 157.69 & \pm 344.12 & \pm 126.61 & \pm 233.99 \\
\hline $\begin{array}{l}\text { ANOVA between } \\
\text { days }\end{array}$ & $\begin{array}{c}\mathrm{p}=0.78 \\
\mathrm{n}=6 \\
\mathrm{df}=5\end{array}$ & $\begin{array}{c}\mathrm{p}=0.16 \\
\mathrm{n}=6 \\
\mathrm{df}=5\end{array}$ & $\begin{array}{c}\mathrm{p}=0.05 \\
\mathrm{n}=6 \\
\mathrm{df}=6\end{array}$ & $\begin{array}{c}\mathrm{p}=0.34 \\
\mathrm{n}=7 \\
\mathrm{df}=6\end{array}$ \\
\hline
\end{tabular}

chi-square test. The size distributions of krill caught in the uppermost depth interval $(30$ to $5 \mathrm{~m}$ ) were compared to those in the lowermost depth interval $(100$ to $80 \mathrm{~m})$ at $02: 00 \mathrm{~h}$, when the vertical segregation in the population was seen to be at its maximum. The size of both males and females in the uppermost samples were not significantly different to those in the deepermost samples. This indicates that migration behaviour in krill was not influenced by size in either sex (females: $\mathrm{n}=1392, \chi^{2}=0.947,0.25<$ $\mathrm{p}<0.5$; males $\mathrm{n}=1000 \chi^{2}=0.845,0.25<$ $\mathrm{p}<0.5)$.

\section{Vertical distribution of moulting krill} during night-time and that females were more likely to migrate into the surface layers.

This general pattern matched well with the female: male ratios observed in the samples preserved in formalin for detailed development staging. In the sample taken at $80 \mathrm{~m}$ on 25 July 1998 at 14:00 h, the female: male ratio was approximately $2: 1(0.7: 0.3)$ whilst in the samples taken at 3 different depths on the 1 August 1998 at 02:00 h, the krill were almost exclusively female in the surface layer, mostly male in the deepest depth interval and present in equal proportions at

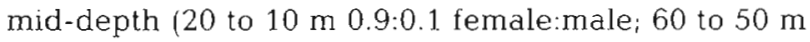

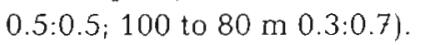

Size differences between migrating and non-migrating krill were examined using a sample median
Fig. 5 presents the proportion of moulting and nonmoulting males and females in each depth interval at 02:00 h, averaged over the study period. Moulting males and females showed very similar vertical distribution patterns, with almost $90 \%$ of moulting krill being found below $65 \mathrm{~m}$ and the majority of these being in the deepest depth interval (100 to $80 \mathrm{~m})$. The vertical distribution of non-moulting krill differed significantly between males and females. The majority of non-moulting females were found in the upper depth intervals at night $(65 \%$ above $65 \mathrm{~m})$ whilst non-moulting males were more evenly distributed through the water column ( $38 \%$ above $65 \mathrm{~m}$ ). Non-moulting males

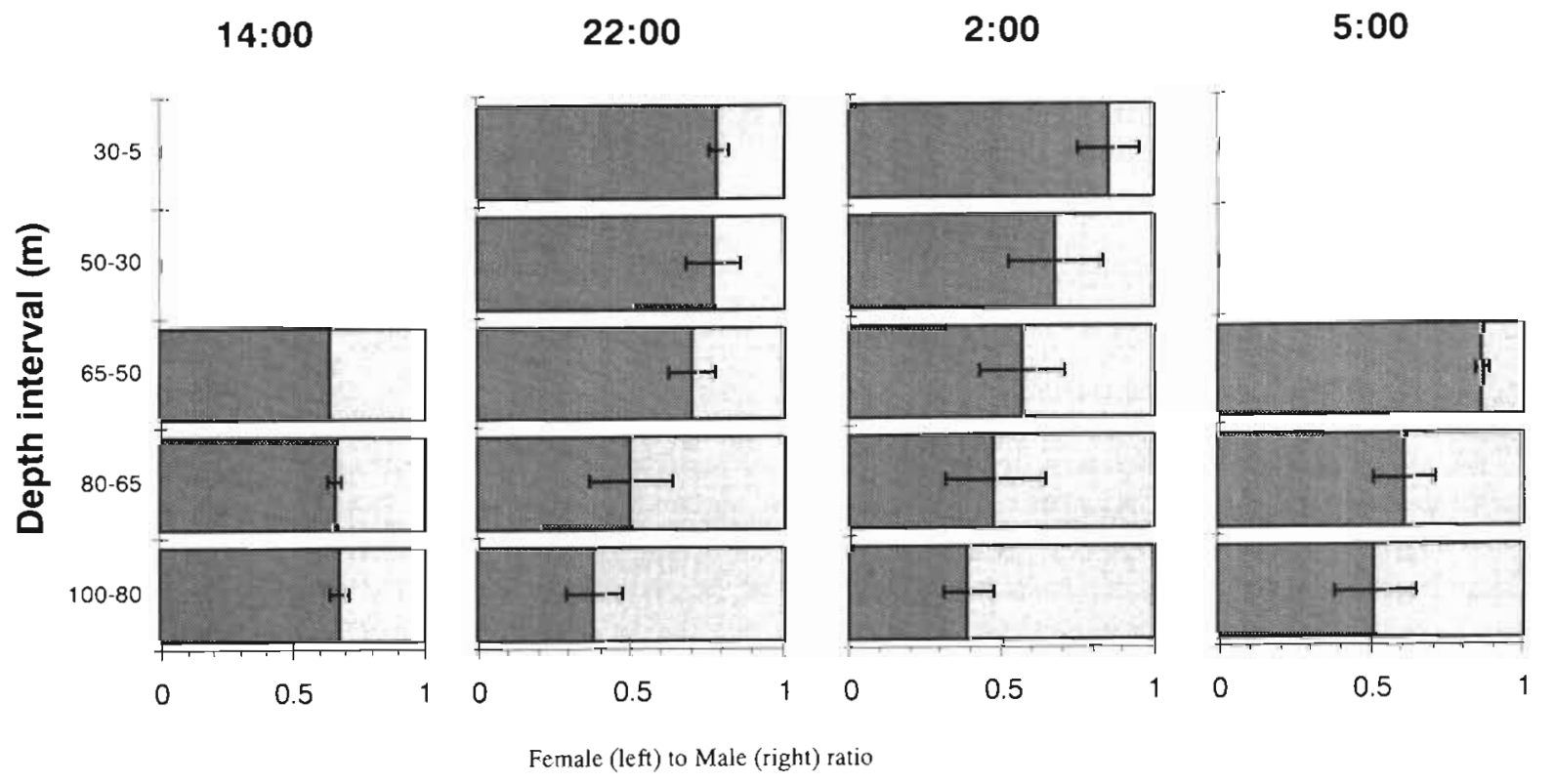

Fig. 4. Female to male ratio at discrete time and depth intervals averaged over 7 full day/night cycles within the period 24 July to 3 August 1998 (with $95 \%$ confidence intervals) 

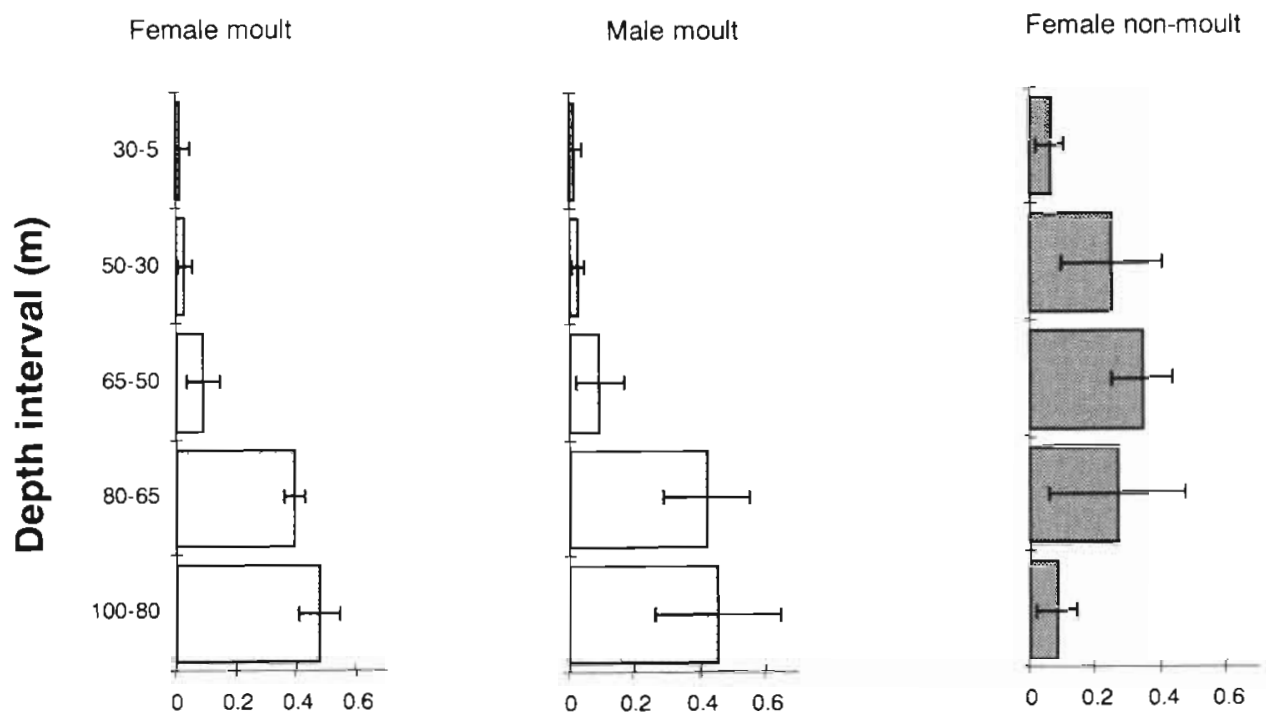

Proportion within the water column

Fig. 5. Vertical distribution of moulting and non-moulting females and males at 02:00 h. Proportions were calculated for each individual day by dividing the number of individuals within a category (e.g. non-moulting males) at a particular depth interval by the total number of individuals within that category throughout the entire water column. The average and $95 \%$ confidence intervals were calculated for 7 full day/night cycles within the period 24 July to 3 August 1998

were significantly more abundant than non-moulting females in the deepest depth interval ( $p=0.001)$

Table 3 presents the data obtained from the staging of moult and reproductive cycles of preserved samples. The percentages were calculated relative to the total number of individuals sampled within the depth interval. Virtually no moulting krill were found in the daytime $(14: 00 \mathrm{~h})$ sample. Moulting krill were found during night-time $(02: 00 \mathrm{~h})$ samples although they were less abundant than non-moulting individuals. As with previous results, the greatest percentages were found in the deeper layers, with 25\% (12\% female, $13 \%$ male) moulting in the 100 to $80 \mathrm{~m}$ sample on 1 August at 02:00 h. The uppermost samples were dominated by non-moulting krill such that only $3 \%$ of individuals between 60 and $50 \mathrm{~m}$ and no individuals between 20 and $10 \mathrm{~m}$ were found to be moulting. The numbers of non-moulting females found to be at either postmoult or premoult were approximately equal (46 and 56\% respectively). By contrast, non-moulting females in the 100 to $80 \mathrm{~m}$ sample were dominated by krill in the postmoult rather than premoult phase $(70 \%$ postmoult; $30 \%$ premoult), which suggests that females reside in the deep for more than 1 day/night cycle after undertaking a moult.

\section{Vertical distribution of spawning krill}

The vertical distribution of the ready to spawn (bluegrey) females is presented in Fig. 6 for the 02:00 h samples, since it is the period of maximum vertical dispersion of the population (see Fig. 3). The percentage values in Fig. 6 were calculated by dividing the num-

Table 3. Number of individuals and percentage (in parentheses) of moulting and non-moulting krill in preserved samples taken at 14:00 h (25 July 1998) at $80 \mathrm{~m}$ and at $02: 00 \mathrm{~h}$ (1 August 1998) at 3 depth intervals in the Alkor Deep

\begin{tabular}{|lccccc|}
\hline Time/depth interval & $\begin{array}{c}\text { Female } \\
\text { moult }\end{array}$ & $\begin{array}{c}\text { Female } \\
\text { non-moult }\end{array}$ & $\begin{array}{c}\text { Male } \\
\text { moult }\end{array}$ & $\begin{array}{c}\text { Male } \\
\text { non-moult }\end{array}$ & $\begin{array}{c}\text { Total } \\
\text { individuals }\end{array}$ \\
\hline 25 July 1998 & $2(0.5 \%)$ & $258(68 \%)$ & $2(0.5 \%)$ & $119(31 \%)$ & 381 \\
$14: 00 \mathrm{~h} / 80 \mathrm{~m}$ & & & & & \\
1 August 1998 & $0(0 \%)$ & $67(94 \%)$ & $0(0 \%)$ & $4(6 \%)$ & 71 \\
$02: 00 \mathrm{~h} / 20-10 \mathrm{~m}$ & $12(2 \%)$ & $340(52 \%)$ & $4(1 \%)$ & $296(45 \%)$ & 652 \\
$02: 00 \mathrm{~h} / 60-50 \mathrm{~m}$ & $34(12 \%)$ & $53(19 \%)$ & $37(13 \%)$ & $151(55 \%)$ & 275 \\
$02: 00 \mathrm{~h} / 100-80 \mathrm{~m}$ & & & & \\
\hline
\end{tabular}




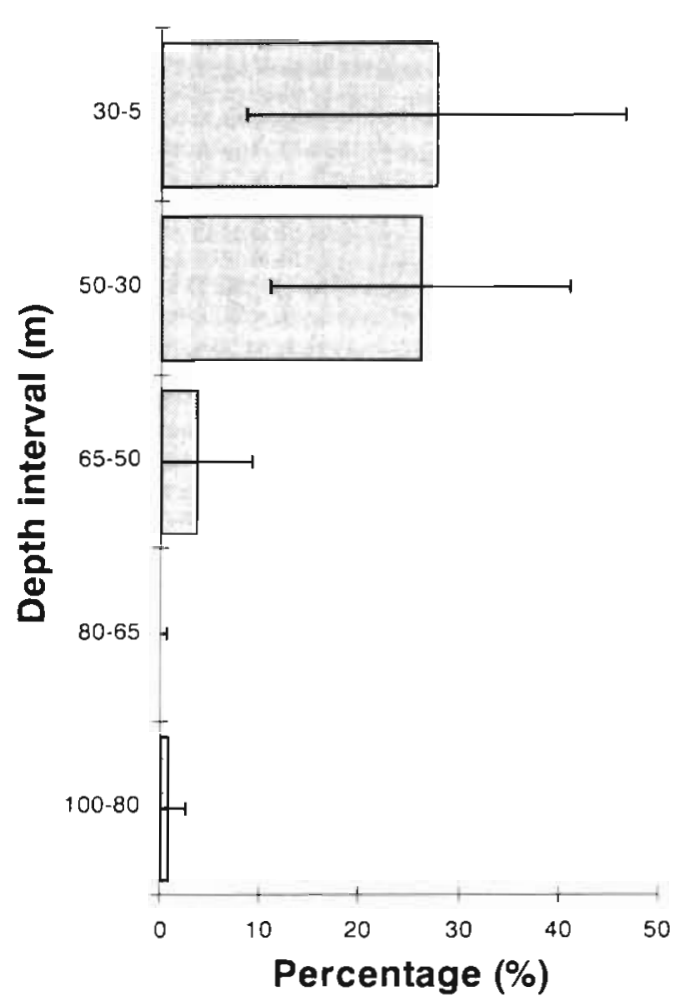

Fig. 6. The number of ready to spawn female Meganyctiphanes norvegica divided by the total number of female $M$. norvegica (as a percentage) in each depth interval at $02: 00 \mathrm{~h}$, averaged over 4 full day/night cycles between 31 July and 3 August 1998 (with $95 \%$ confidence intervals)

ber of ready to spawn females by the total number of females in each depth layer and subsequently averaging over the period of 4 day/night cycles from 31 July to 3 August. The percentage of ready to spawn females was significantly higher in the uppermost depth intervals (between 50 and $5 \mathrm{~m}$ ) than in the deeper depth intervals, where ready to spawn females made up, on average, less than $4 \%$ of the total catch.

Table 4 presents the data obtained from the detailed analysis on the SDS of female krill in the preserved sample from 1 August at 02:00 h. Percentages were calculated relative to the total number of females caught within each depth interval. The data show the

Table 4. Number of individuals and percentage (in parentheses) of vitellogenic, ready to spawn and postspawn female krill in preserved samples from 3 depth intervals at $02: 00 \mathrm{~h}$ on 1 August 1998

\begin{tabular}{|c|c|c|c|c|}
\hline \multirow[t]{2}{*}{ Depth $(m)$} & \multicolumn{4}{|c|}{ No. female krill ( $\%$ in sample) } \\
\hline & Vitellogenic & Ready to spawn & Postspawn & Total females \\
\hline $20-10$ & $16(24)$ & $44(66)$ & $7(10)$ & 67 \\
\hline $60-50$ & $120(34)$ & $116(32)$ & $120(34)$ & 356 \\
\hline $100-80$ & $36(41)$ & $5(6)$ & $46(53)$ & 87 \\
\hline
\end{tabular}

same trend as observed in the 7 day/night series of samples (Fig. 6). The percentage of ready to spawn females (i.e. with ovaries containing mature oocytes, SDS 4 and SDS 51) was the highest in the uppermost depth interval $(66 \%)$. Of the other categories, vitellogenic females were more than twice as abundant as postspawn females in the uppermost depth interval. In the lower depth intervals, however, vitellogenic and postspawn krill showed similar proportions, which was taken as an indication that female krill do not come into the surface layers after spawning has been completed.

Examination of female sexual development in the preserved samples taken at $14: 00 \mathrm{~h}$ on 25 July revealed that $45 \%$ of females were ready to spawn the following night (late SDS 3, SDS 4 and SDS $5_{1}$ ). Given that this sample was taken at $80 \mathrm{~m}$, where the maximum concentration of krill resided at this time of day, these results indicate that a relatively large percentage of the female population moves into the upper layers to spawn at night. However, the average concentration of krill caught in the upper depth intervals is relatively small (see Fig. 3). Therefore, it is likely that after the ready to spawn females have migrated upwards, they spread over a much wider geographic area, which lowers their apparent concentration above the Alkor Deep.

Overall, these results indicate that there is a reverse trend between a vertical migration of females into the upper layers at night for spawning and residency of both males and females in the deeper layers for moulting.

\section{DISCUSSION}

Data on vertical distribution of northern krill showed that there was a consistent pattern of segregation during the upward vertical migration phase at night-time. Although the largest part of the krill population was seen between 80 and $50 \mathrm{~m}$ during night-time, a certain fraction was always evident in the deepest (100 to $80 \mathrm{~m}$ ) and shallowest ( 30 to $5 \mathrm{~m}$ ) depth intervals. The comparison of the size frequency distribution of krill in the top and bottom depth intervals failed to show any significant differences in total bodylength. However, significant differences between the deepest and shallowest depth intervals were evident in the sex ratio, moulting and spawning states of the krill. Therefore, night-time segregation of the population does not appear to be a passive process resulting from differential swimming or sinking rates which vary according to size (Worthington 1931, Hardy \& Gunther 1935, Mauch- 
line 1980, Kils 1981) but an active behavioural response to internal physiological processes and external intra-specific stimuli (sensu Watkins et al. 1992).

Cuzin-Roudy \& Buchholz (1999) illustrated that moulting and spawning in female krill are interlinked processes. Eggs are released during the early premoult phase of the developmental cycle in 1,2 or 3 spawning events. Then, moulting occurs several days after spawning has been completed (3 d in July 1996. Kattegat; Cuzin-Roudy \& Buchholz 1999). During moulting, female krill lose the sperm mass because the process involves the exuviation of the thelycum. Directly after moulting, krill are flaccid and the females are ready to be newly mated.

The moulting of Antarctic krill at night has been observed in a number of previous studies where krill were maintained in laboratory conditions (Murano et al. 1979, Morris \& Keck 1984, Nicol 1989, Buchholz 1991), and also for northern krill (Cuzin-Roudy \& Buchholz 1999). However, the further observation that this moulting takes place in the deepest layers has not been previously reported for euphausiid species that vertically migrate, such as Meganyctiphanes norvegica. There may be a number of possible explanations for this phenomenon. Firstly, although krill continue to be able to swim during ecdysis through maintaining muscle attachments to both the old and the new cuticle (Buchholz \& Buchholz 1989), it is unlikely that they are able to achieve a high performance potential. This is because the changes in water balance and structure of the cuticle are likely to increase basal metabolism (Buchholz 1991). Therefore, there may not be enough surplus energy to perform vertical migration during this period of the developmental cycle. Secondly, given that moulting krill cannot feed because of the exuviation of the stomach lining, the high food densities at the surface (J. B. L. Matthews unpubl. data) are no longer relevant and energy may be saved in not migrating. Thirdly, the lack of a hard exoskeleton may make krill more vulnerable to predation by other carnivorous zooplankton including their own species. Cannibalism was frequently observed during maintenance experiments carried out on the present and previous sampling missions, and the presence of euphausiid compound eyes in krill stomachs led Fisher \& Goldie (1959) to conclude that cannibalism was a common phenomenon at certain times of the year Moulting in the deep during night-time would be a suitable strategy for avoiding cannibalism since a large fraction of non-moulting individuals have migrated into the upper strata at this time.

Apart from moulting individuals, a large proportion of krill residing in the deep during night-time were non-moulting males. Given that females are ready to be remated once newly moulted, the potential to mate may induce a certain fraction of non-moult males to remain in the deep at night. This may result from the release of a pheromone by females which attracts males and overcomes those factors that would ordinarily induce them to migrate vertically. This mechanism has been previously suggested by Buchholz et al. (1996), who found certain swarms of Euphausia superba were made up of reproducing adult males and females, and recently moulted females were always rapidly mated. Work on krill sex pheromones has not yet been carried out but it is known that E. superba does respond to chemical cues in relation to feeding activity (Hamner et al. 1983).

Contrary to the vertical distribution of moulting krill, the largest proportion of ready to spawn female krill was found in the uppermost part of the water column $(30$ to $5 \mathrm{~m}$ ) during night-time. The swarming of Meganyctiphanes norvegica at the surface has been reported previously by Nicol (1984) in the Bay of Fundy. The majority of surface swarms were dominated by females in pre- and post-spawning condition and the simultaneous occurrence of large numbers of krill eggs in the surface plankton indicated that these swarms were engaged in reproductive behaviour. Furthermore, swarms were principally made up of larger krill from the Group II ( 2 yr old) cohort so it was concluded that the behaviour was an ontogenic migration by a particular age group (Nicol 1984). In the present investigation, the trend for spawning in the surface layers was principally linked to normal diel vertical migration behaviour and there was no significant size differences between those females spawning at the surface and those found in the deepest depth intervals at night. In this instance therefore, it seems that there is a functional relationship between the ovarian cycle for egg production and the diel cycle of vertical migration to enable the release of eggs in the surface water.

Ready to spawn females are loaded with lipid-rich oocytes (Cuzin-Roudy et al. 1999) which may decrease body density and enhance buoyancy. This is likely to reduce the energetic cost of vertical migration for ready to spawn females and makes their migration into the upper layers less energetically expensive than for males and non-spawning females which do not possess the equivalent lipid reserves. Migration to the surface may benefit ready to spawn females because the higher temperature (up to $16^{\circ} \mathrm{C}$ ) will accelerate oocyte maturation in the ovary through speeding up final meiosis. It will also accelerate the corresponding moult stages $\left(D_{0}\right.$ and $D_{1}$ ) that are interlinked with the spawning events (Cuzin-Roudy \& Buchhol\% 1999). What results is a faster maturation and more rapid release of eggs, allowing the krill to immediately enter another cycle of egg preparation (i.e. a vitellogenic moult cycle). 
Releasing eggs in the higher temperatures near the surface also accelerates embryonic development and reduces the time to the hatching of the nauplii. The fact that the surface waters are relatively brackish 20 to 25 PSU) means that the osmotic potential would act to increase the water content of the eggs. Marschall (1983) showed that transferring eggs from 33 to 30 PSU made the inner diameter of the egg swell, thus slowing the sinking speed. Marschall $(1982,1983)$ further described the descent of embryos, hatching and the reascent of the nauplii of Meganyctiphanes norvegica in the Kattegat during August 1981, when environmental conditions were similar to those present during this study. The embryos were found to be abundant at a depth of $25 \mathrm{~m}$ but they hatched into the non-feeding nauplii stage no deeper than $60 \mathrm{~m}$. From experiments carried out by Marschall (1983) the duration of the embryonic period was found to be $2.5 \mathrm{~d}$ at $10^{\circ} \mathrm{C}$, by which time the embryo would have sunk between 190 and $290 \mathrm{~m}$ in still waters. This means that if the eggs had been released below the thermocline at $40 \mathrm{~m}$, they would have arrived at the bottom before hatching and consequently perished. Spawning above the thermocline, close to the surface, means that the eggs are released into water temperatures close to $16^{\circ} \mathrm{C}$, which would result in the embryonic developmental time being half of that observed at $10^{\circ} \mathrm{C}$ (Marschall 1983). Both the higher temperature and lower salinity at the surface act to decrease the depth to which the egg sinks before hatching. Given that Marschall (1982) found the feeding nauplii stages within the chlorophyll maximum at $20 \mathrm{~m}$, the potential success of eggs would increase the higher in the water column they are released. This is because the distance that newly hatched larvae must swim during their ascent to the layer of maximum food abundance is reduced. Therefore, egg release by females in the upper level of the water column can be viewed as a strategy to optimise embryonic development and bring larvae into the right feeding environment at the appropriate time for further development.

Diel vertical migration of euphausiids is a complex behaviour influenced by a number of factors including the physical environment (Greene et al. 1992, Tarling et al. 1998), feeding (Simard et al. 1986), light and predators (Onsrud \& Kaartvedt 1998). Here we have demonstrated that, during the reproductive season, the physiological processes of reproduction and moulting affect krill vertical migration behaviour. Normal diel vertical migration may be inhibited so that individual krill remain in the deep to moult and mate, or otherwise altered so that females leave the main swarm and enter the surface layers for spawning. The consequence is a night-time vertical segregation of krill according to both sex and the stage they have reached in the moulting and reproductive cycles.
Acknowledgements. We would like to thank the following people for their assistance in collecting and subsequent sorting of net samples: S. Bröhl, C. Buchholz, M. Hatherell, J. B. L. Matthews, R. Saborowski. M. Salomon and P. Virtue. We would also like to acknowledge the support and efficiency of the crew of the RV 'Heincke' This project was funded by EUMAST III (Marine Science and Technology Programme). The Physiological Ecology of a Pelagic Crustacean (PEP) Project (MAS3-CT-0013).

\section{LITERATURE CITED}

Bămstedt U, Karlson K (1998) Euphausiid predation on cope pods in coastal water of the Northeast Atlantic. Mar Ecol Prog Ser 172:149-168

Boucher J, Thiriot A (1972) Zooplancton et micronecton estivaux des deux cents premiers metres en Mediterranée Occidentale. Mar Biol 15:47-56

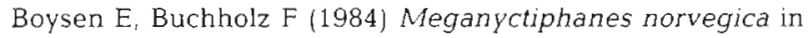
the Kattegat. Studies on the annual development of a pelagic population. Mar Biol 79:195-207

Buchholz C, Buchholz F (1989) Ultrastructure of the integument of a pelagic crustacean: moult cycle related studies on the Antarctic krill, Euphausia superba. Mar Biol 101. $355-365$

Buchholz F (1991) Moult cycle and growth of Antarctic krill Euphausia superba in the laboratory. Mar Ecol Prog Ser 69:217-229

Buchholz F, Boysen-Ennen E (1988) Meganyctiphanes norvegica (Crustacea: Euphausiacea) in the Kattegat: studies on the horizontal distribution in relation to the hydrography and zooplankton. Ophelia 29:71-82

Buchholz F, Buchholz C. Reppin J, Fisher J (1995) Diel vertical migrations of Meganyctiphanes norvegica in the Kattegat: comparison of net catches and measurements with Acoustic Doppler Current Profilers. Helgol Wiss Meeresunters 49:849-866

Buchholz F, Watkins JL, Priddle J, Morris DJ, Ricketts C (1996) Moult in relation to some aspects of reproduction and growth in swarms of Antarctic krill, Euphausia superba. Mar Biol 127:201-208

Cuzin-Roudy J (1993) Reproductive strategies of the Mediterranean krill, Meganyctiphanes norvegica and the Antarctic krill Euphausia superba (Crustacea: Euphausiacea). Invertebr Reprod Dev 23:105-114

Cuzin-Roudy J, Buchholz F (1999) Ovarian development and spawning in relation to the moult cycle in northern krill Meganyctiphanes norvegica (Crustacea: Euphausiacea), along a climatic gradient. Mar Biol 133:267-281

Cuzin-Roudy J, Albessard E, Virtue P, Mayzaud P (1999) The scheduling of spawning with the moult cycle in northern krill (Crustacea: Euphausiacea): a strategy for allocating lipids to reproduction. Invertebr Reprod Dev 36:163-170

Fisher LR, Goldie EH (1959) The food of Meganyctiphanes norvegica ( $M$. Sars) with an assessment of the contributions of its components to the vitamin $A$ reserves of the animal. J Mar Biol Assoc UK 38:291-31.2

Greene $\mathrm{CH}$, Widder EA, Marsh J, Youngbluth MJ, Tamse A, Johnson GE (1.992) The migration behavior, fine structure and biolumescent activity of krill sound-scattering layers. Limnol Oceanogr 37:650-658

Hamner WN, Hamner PP, Strand SW, Glimer RW (1983) Behaviour of Antarctic krill, Euphausia superba: chemoreception, feeding, schooling and molting. Science 220: 433-435 
Hardy AC, Gunther ER (1935) The plankton of the South Georgia whaling ground and adjacent waters, 1926-27. Discovery Rep 11: 1-456

Kaartvedt S, Melle W, Knutsen T, Skjoldal HR (1996) Vertical distribution of fish and krill beneath water of varying optical properties. Mar Ecol Prog Ser 136:51-58

Kils U (1981) Swimming behaviour, swimming performance and energy balance of Antarctic krill Euphausia superba. Biomass Sci Ser 3:1-121

Lindley JA (1982) Population dynamics and production of euphausiids III. Meganyctiphanes norvegica and Nyctiphanes couchi in the north Atlantic ocean and the North Sea. Mar Biol 66:37-46

Longhurst AR (1976) Vertical migration. In: Cushing DH, Walsh JJ (eds) The ecology of the seas. Blackwell Scientific Publications, Oxford, p 116-137

Marschall HP (1982) Über die Larvenstadien von Meganyctiphanes norvegica (M. Sars) im Läsö-Tief, Kattegat. Diploma thesis, Institut für Meereskunde und Institut für Polarökologie, Christian-Albrechts Universität, Kiel

Marschall HP (1983) Sinking speed, density and size of euphausiid eggs. Meeresforschung 30:1-9

Matthews JBL, Buchholz F, Tarling GA, Saborowski R, Dallot $S$, Labat JP (1999) On the physical oceanography of the Kattegat and Clyde Sea area, as background to ecophysiological studies of the planktonic crustacean, Meganyctiphanes norvegica. Helgol Mar Res 53:70-84

Mauchline J (1960) The biology of the euphausiid crustacean, Meganyctiphanes norvegica Sars. Proc R Soc Edin B 67 : $141-179$

Mauchline J (1980) The biology of mysids and euphausids Adv Mar Biol 18:1-681

Mauchline J, Fisher LR (1969) The biology of euphausiids. Adv Mar Biol 7:1-454

Morris DJ, Keck A (1984) The time course of the moult cycle and growth of Euphausia superba in the laboratory. A preliminary study. Meeresforschung 30:94-100

Murano M, Segawa S, Kato M (1979) Moult and growth of Antarctic krill in the laboratory. Trans Tokyo Univ Fish 3:99-106

Nicol S (1984) Population structure of daytime surface swarms of the euphausiid Meganyctiphanes norvegica in the Bay of Fundy. Mar Ecol Prog Ser 18:241-251

Nicol S (1989) Apparent independence of spawning and moulting cycles in female krill (Euphausia superba Dana). Polar Biol 9:371-375

Editorial responsibility: Otto Kinne (Editor),

Oldendorf/Luhe, Germany
Onsrud MSR, Kaartvedt S (1998) Diel vertical migration of the krill Meganyctiphanes norvegica in relation to physical environment, food and predators. Mar Ecol Prog Ser $171: 209-219$

Sameoto DD (1980) Relationships between stomach contents and vertical migration in Meganyctiphanes norvegica, Thysanoessa raschii and $T$. inermis (Crustacea Euphausiacea). J Plankton Res 2:129-143

Simard Y, Lacroix G, Legendre L (1986) Diel vertical migrations and nocturnal feeding of a dense coastal krill scattering layer (Thysanoessa raschii and Meganyctiphanes norvegical in stratified surface waters. Mar Biol 91:93-105

Tarling GA, Matthews JBL, Saborowski R, Buchholz F (1998) Vertical migratory behaviour of the euphausiid Meganyctiphanes norvegica, and its dispersion in the Kattegat Channel. Hydrobiologia 375/376:331-341

Tarling GA, Buchholz F, Matthews JBL (1999) The effect of a lunar eclipse on the vertical migration of Meganyctiphanes norvegica (Crustacea: Euphausiacea) in the Ligurian Sea. J Plankton Res 21:1475-1488

Velsch JP (1997) Dynamique de population et migrations verticales journalières de Meganyctiphanes norvegica (Crustacés: Euphausiacés) en Mediterranée Nord-Occidentale. Thèse de doctorat, Université d'Aix Marseille II

Watkins JL, Buchholz F, Priddle J, Morris DJ, Ricketts C (1992) Variation in reproductive status of Antarctic krill swarms; evidence for a size-related sorting mechanism? Mar Ecol Prog Ser 82:163-174

Wiebe PH, Burt KH, Boyd SH, Morton AW (1976) A multiple opening/closing net and environmental sensing system for sampling zooplankton. J Mar Res 34:313-326

Wiebe PH, Morton AW, Bradley AM, Backus RH, Craddock JE, Barber V, Cowles TJ, Flierl GR (1985) New developments in the MOCNESS, an apparatus for sampling zooplankton and micronekton. Mar Biol 87:313-323

Worthington RS (1931) Vertical movements of freshwater macroplankton. Int Rev Hydrobiol 25: 394-436

Youngbluth MJ, Bailey TG, Davoll PJ, Jacoby CA, BladesEckelbarger PI, Griswold CA (1989) Fecal pellet production and diel migratory behaviour of the euphausiid Meganyctiphanes norvegica effect benthic-pelagic coupling. Deep-Sea Res 36:1491-1501

Zar JH (1996). Biostatistical analysis. Prentice Hall International, Englewood Cliffs, NJ

Submitted: May 21, 1999; Accepted: October 12, 1999

Proofs received from author(s): November 17. 1999 